\title{
ENRAIZAMENTO DE ESTACAS DE TRÊS ESPÉCIES SILVESTRES DE Passiflora ${ }^{1}$
}

\author{
MARCELO FIDELES BRAGA ${ }^{2}$, ERIVANDA CARVALHO DOS SANTOS ${ }^{3}$, NILTON TADEU VILELA JUNQUEIRA ${ }^{4}$, \\ ALEX ANTONIO TORRES CORTES DE SOUSA ${ }^{5}$, FÁBIO GELAPE FALEIRO ${ }^{3}$, LEYLANNE NOGUEIRA REZENDE ${ }^{4}$, \\ KEIZE PEREIRA JUNQUEIRA ${ }^{6}$
}

\begin{abstract}
RESUMO - Em ambiente com nebulização controlada, estacas herbáceas com um par de folhas, contendo 2 ou 3 nós, foram testadas quanto ao enraizamento, utilizando-se de bandeja de poliestireno com célula de $95 \mathrm{~cm}^{3}$ e saco plástico de $15 \times 25 \times 0,02 \mathrm{~cm}$ com $1.730 \mathrm{~cm}^{3}$. Foram testadas estacas de Passiflora actinia, P. serrato-digitata e $P$. setacea. Observou-se que $P$. serrato-digitata apresentou 94,3\% de estacas enraizadas com brotos e 2,4\% de mortalidade; enquanto $P$. actinia e $P$. setacea apresentaram, respetivamente, $30,5 \%$ e $28,6 \%$ de estacas enraizadas com brotos e $56,8 \%$ e $60,7 \%$ de mortalidade. A alta mortalidade das estacas foi atribuída ao estado fenológico das matrizes de $P$. actinia e $P$. setacea e ao ataque de larvas de bradisia (Bradysia spp.) Estacas com dois e três nós não apresentaram diferenças significativas, e o recipiente saco plástico de $1.730 \mathrm{~cm}^{3}$ proporcionou melhor desenvolvimento das mudas.
\end{abstract}

Termos para indexação: maracujá, $P$. actinia, P. serrato-digitata, . setacea, estaquia, recipiente.

\section{CUTTING ROOTING OF THREE WILD PASSIFLORA SPECIES}

\begin{abstract}
Steam cuttings of three wild Passiflora species where tested for rooting in a mist regulated greenhouse. Cuttings with two or three buds were used with two kinds of containers: polystyrene trays with $95 \mathrm{~cm}^{3}$ cells and perforated plastic bags of $15 \times 25 \times 0.02 \mathrm{~cm}$, with $1,730 \mathrm{~cm}$. Passiflora serrato-digitata was the best, with $94.3 \%$ of rooted cuttings with shoots e only $2.4 \%$ of death cuttings. P. actinia and P. setacea showed, respectivelly, $30.5 \%$ and $28.6 \%$ of rooted cuttings and $56.8 \%$ and $60.7 \%$, of death cuttings. The high death were attribute to phenological phases of $P$. actinia and $P$. setacea or injury caused by fungus-gnat larvae (Bradysia spp.). Cuttings with two or three buds didn't show differences among them. Plastic bags proporcioned the best results, increasing rooted cuttings and plant development.
\end{abstract}

Index terms: Passion fruit, P. actinia, P. serrato-digitata, . setacea, cutting, container.

\section{INTRODUÇÃO}

No Brasil, algumas regiões de cultivo comercial de maracujáamarelo (Passiflora edulis f. flavicarpa DEG) enfrentam problemas com patógenos de solo, que têm causado sérios prejuízos e até mesmo inviabilizado a cultura em determinadas áreas. Ainda não existe uma cultivar resistente, sendo um dos desafios para o melhoramento genético. Uma solução a curto prazo seria o uso de mudas enxertadas. A enxertia em maracujá é uma técnica recomendada por vários autores (Maldonado, 1991; Menezes et al., 1994; Hartmann et al., 1997; Ruggiero e Oliveira, 1998; Junqueira et al., 2002; Chaves et al., 2004; Lima e Trindade, 2004). Na escolha do porta-enxerto, devem ser considerados os patógenos do solo que atacam a cultura; as espécies resistentes a estes patógenos; os método de propagação; a compatibilidade para enxertia, e a produtividade.

A murcha de fusarium, causada pelo fungo Fusarium oxysporum Schl. f. passiflorae Purss, e a podridão de fusarium, causada pelo fungo Fusarium solani (Mart.) Sacc. (forma assexuada de Nectria haematococca Berk \& Br.), e a podridão do colo, causada por Phytophthora sp, são as principais doenças causadas por patógenos do solo que atacam a cultura do maracujá-amarelo. Essas doenças não têm tratamento curativo. O controle é feito de forma preventiva: usar sementes de matrizes sadias, evitar solos arenosos, solos mal drenados e áreas récem-desmatadas (alta matéria orgânica) e erradicar plantas sintomáticas. Outra possibilidade é a utilização de porta-enxertos resistentes. Em espécies silvestres de maracujá, existe alta variabilidade em relação à resistência, suscetibilidade e tolerância a essas doenças (Pio-Ribeiro e Mariano, 1997; Santos Filho, 1998; Roncatto et al., 2004 e Fisher et al., 2005). Já para Fisher et al. (2005), não existem espécies de passiflora resistentes às podridões de fusarium e do colo.

Dentre as espécies da coleção de trabalho da Embrapa Cerrados, Passiflora actinia Hooks. Passiflora setacea DC. e
Passiflora serrato-digitata L., têm apresentado excelente desenvolvimento e vigor numa área com histórico de ocorrência de murcha de fusarium, podridão de fusarium, podridão do colo e do vírus do endurecimento do fruto (PWV). Desta forma, essas três espécies têm despertado interesse em testar sua viabilidade como porta-enxerto. Entretanto, um dos primeiros obstáculos para o uso dessas espécies para esta finalidade é o diâmetro muito fino do caule das plântulas obtidas por sementes, dificultando a operação de enxertia, já que os garfos viáveis de maracujá-amarelo têm diâmetros superiores aos apresentados por essas plântulas em fase de viveiro. No caso de $P$. setacea, outro fator limitante é a dormência das sementes, que pode durar até dois anos (Meletti et al., 2002). Segundo Chaves et al. (2004), a enxertia em estacas enraizadas seria a solução, pois, além de apresentarem diâmetro maior que as plântulas, as estacas apresentam a vantagem da clonagem, conferindo mais uniformidade às mudas obtidas.

O objetivo desse trabalho foi testar o enraizamento de três espécies silvestres de maracujá: Passiflora actinia, Passiflora setacea e Passiflora serrato-digitata.

\section{MATERIAIS E MÉTODOS}

O delineamento experimental foi o de blocos ao acaso, em esquema fatorial $3 \times 2 \times 2$, sendo três espécies, dois tipos de estacas e dois tipos de recipientes, num total de 12 tratamentos, repetidos em 3 blocos, sendo cada unidade experimental composta por 6 estacas.

As estacas foram obtidas de ramos do ano, em matrizes da coleção de trabalho da Embrapa Cerrados, Planaltina-DF, entre os dias 23 e 24-02-2005, de três espécies: P. actinia, P. setacea e P. serratodigitata. Estacas semi-herbáceas, de três e de dois nós, mantidas duas folhas expandidas na parte distal, foram coletadas e imediatamente plantadas em dois tipos de recipientes: em bandeja de poliestireno, com 72 células, cada célula com $12 \mathrm{~cm}$ de profundidade e preenchida

\footnotetext{
${ }^{1}$ (Trabalho 178-2005). Recebido: 26-10-2005. Aceito para publicação: 23-06-2006.

2 Pesquisador Embrapa Cerrados, fideles@cpac.embrapa.br; Caixa Postal 08223, CEP.:73.310-970, Planaltina-DF.

${ }^{3}$ Estagiário da Embrapa Cerrados, aluno da UPIS/DF; erivanda@cpac.embrapa.br.

${ }^{4}$ Pesquisador Embrapa Cerrados.

${ }^{5}$ Estagiário da Embrapa Cerrados, aluno da UPIS/DF.

${ }^{6}$ Mestranda UFLA-MG.
} 
TABELA 1 - Resultados médios obtidos de 3 espécies de maracujá em função de 06 variáveis avaliadas referentes a estacas vivas. Brasília-DF (2005).

\begin{tabular}{|c|c|c|c|c|c|c|c|}
\hline \multirow{2}{*}{$\begin{array}{c}\text { Espécies: } \\
\text { Estacas Vivas }\end{array}$} & \multicolumn{2}{|c|}{$P$.actinea } & \multicolumn{2}{|c|}{ P. setacea } & \multicolumn{2}{|c|}{ P. serrato-digitata } & \multirow[b]{2}{*}{$\mathrm{CV} \%$} \\
\hline & $\mathrm{n}$ & Média* & $\mathrm{n}$ & Média * & $\mathrm{n}$ & Média * & \\
\hline Sem calo $(\%)^{(1)}$ & 12 & $1,2 \mathrm{a}$ & 12 & $0,0 \mathrm{a}$ & 12 & $1,2 \mathrm{a}$ & 9,1 \\
\hline Com calo $(\%)^{(1)}$ & 12 & $10,2 \mathrm{~A}$ & 12 & $3,7 \mathrm{AB}$ & 12 & $0,0 \mathrm{~B}$ & 15,4 \\
\hline Enraizadas s/ broto (\%) & 11 & $1,3 \mathrm{a}$ & 11 & $7,0 \mathrm{a}$ & 12 & $2,1 \mathrm{a}$ & 16,3 \\
\hline Enraizadas c/ brotos (\%) & 11 & $30,5 \mathrm{~B}$ & 11 & $28,6 \mathrm{~B}$ & 12 & $94,3 \mathrm{~A}$ & 15,0 \\
\hline Comprimento do broto $(\mathrm{cm})^{(2)}$ & 10 & $18,2 \mathrm{~b}$ & 9 & $14,2 \mathrm{~b}$ & 12 & $46,4 \mathrm{a}$ & 17,1 \\
\hline Massa seca raízes/estaca (g) & 11 & $0,0 \mathrm{~B}$ & 10 & $0,1 \mathrm{~B}$ & 12 & $0,2 \mathrm{~A}$ & 0,3 \\
\hline
\end{tabular}

*Médias com mesma letra, na linha, não diferem significativamente, pelo teste de Tukey**, a 5\%

**Para a análise estatística, os dados foram transformados por ${ }^{(1)} \sqrt{x+1} \cdot \mathrm{e}^{(2)} \log (\mathrm{x}+10)$.

com $95 \mathrm{~cm}^{3}$ de substrato organomineral à base de vermiculita, da marca Plantmax HT; e em saco de filme polietileno preto, de $15 \mathrm{~cm}$ de diâmetro, $25 \mathrm{~cm}$ de profundidade e $0,02 \mathrm{~cm}$ de espessura, resultando num volume de $1.730 \mathrm{~cm}^{3}$ por unidade, tendo, na base, uma camada de $12 \mathrm{~cm}$ de substrato composto de terra, esterco de galinha e fertilizantes, e, no topo, uma camada de $10 \mathrm{~cm}$ de substrato Plantmax HT. Foi plantada uma estaca em cada saco ou célula.

O experimento foi instalado em casa de vegetação, sob nebulização controlada por umidostato, acionada para manter a umidade relativa do recinto sempre acima de $60 \%$, durante 30 dias. Após esse período, o experimento foi transferido para recinto com microasperção, duas vezes ao dia, por 48 dias. Tendo completado 78 dias do plantio das estacas, o experimento foi avaliado entre os dias 11 e 13 de maio de 2005.

A avaliação foi feita inicialmente quanto ao número de estacas vivas sem calo, com calo e enraizadas; das enraizadas, contou-se quantas brotaram e o comprimento do broto; e quanto ao número de estacas mortas, sem calo, com calo e enraizadas. Para evitar danos ao sistema radicular e melhor visualização, o substrato de cada estaca foi retirado por lavagem com jato de água moderado. Em seguida, as raízes foram retiradas das estacas e postas a secar em estufa a $75^{\circ} \mathrm{C}$. Após 7 dias, foi medido o peso da massa seca dessas raízes.

Os resultados foram tabulados e submetidos à análise estatística. Primeiramente, foram realizados os testes de uniformidade de variância e de distribuição normal, para averiguar os procedimentos para análise de variância e a necessidade de transformação, conforme preconizado por Little E Hills (1975).

\section{RESULTADOS E DISCUSSÃO}

As variáveis analisadas não apresentaram uniformidade de variância, nem distribuição normal. Em razão disso, foram testadas várias transformações de dados que proporcionassem as condições necessárias para a análise de variância e teste de médias (Little e Hills, 1975). Desta forma, para a análise estatística, os dados foram transformados por $\log (\mathrm{x}+10)$, para as variáveis "comprimento do broto" e "massa seca de raiz por estaca" e por $\sqrt{x+1}$, para as demais variáveis testadas. Para melhor apresentação, as médias das variáveis transformadas foram destransformadas para escala original, e apresentadas na forma de porcentagem; exceto para as variáveis "comprimento do broto" e "peso da raiz por estaca", que foram apenas destransformadas e apresentadas em escala original. Os resultados são apresentados nas Tabelas de 1 a 6 .

Primeiramente, apresentam-se os resultados, considerando apenas o efeitos das três espécies. Na Tabela 1, apresentam-se os resultados referentes a estacas vivas e, na Tabela 2, a estacas mortas. A variável de maior interesse é "estacas enraizadas com brotos", que representa a estaca que completou a formação da muda. Neste caso, pode ser observado, na Tabela 1 , que a espécie $P$. serrato-digitata foi a que obteve maior sucesso na formação de mudas, apresentando 94,3\% das estacas transformadas em mudas (enraizadas e com brotos). As demais espécies não chegaram nem a $1 / 3$ desse resultado, não diferindo entre si. Além de ser a que mais formou mudas, $P$. serratodigitata também foi a que teve maior comprimento de broto e maior massa seca das raízes.

Estes resultados obtidos com $P$. serrato-digitata são superiores aos alcançados por Meletti e Nagai (1992) que, apesar de obterem $72 \%$ de brotação nas estacas desta espécie, o enraizamento foi insignificante, tendo a maioria das estacas desenvolvido apenas calos. São superiores também em relação às espécies comerciais, já que Salomão et al. (2002) obtiveram com P. alata e P. edulis $f$. flavicarpa, respectivamente, $93,5 \%$ e $96 \%$ de estacas enraizadas e $0,11 \mathrm{~g}$ e $0,02 \mathrm{~g}$ de massa seca de raízes por estaca. Em parte, o insucesso de $P$. actinia e $P$. setacea, em formar mudas, pode ser atribuído ao alto índice de mortalidade das estacas dessas espécies (Tabela 2), que ficou entre 56,8 e 60,7\%, diferente, significativamente, de P. serratodigitata, que apresentou apenas $2,4 \%$ de mortalidade.

Segundo Hartmann et al. (1997), em geral, as raízes adventícias, formadas em estacas, têm origem em células vizinhas ao câmbio e ao floema. Geralmente, células do parênquima, devido sua totipotência e estímulo hormonal, diferenciam-se em meristemas radiculares, dando início à formação das raízes. Fatores internos e externos podem estar envolvidos no enraizamento de estacas. Os principais fatores internos são os fitormônios (principalmente auxinas), e os externos são luz, temperatura e umidade; que tanto podem agir durante o enraizamento, como também no condicionamento da plantamatriz (Rodrigues, 1996). Além desses, existe ainda a predisposição genética ao enraizamento, que pode variar entre e dentro das espécies.

Auxinas são produzidas principalmente nos meristemas apicais, mas também podem ser produzidas nas folhas (Woodward e Bartel, 2005). Para Hartmann et al. (1997), o efeito das folhas remanescentes na estaca é, principalmente, devido à produção de auxinas, que serão translocadas para a base da estaca e irão agir na diferenciação dos primórdios radiculares. Além da produção de

TABELA 2 - Resultados médios obtidos de 3 espécies de maracujá em função de 04 variáveis avaliadas, referentes a estacas mortas. BrasíliaDF(2005).

\begin{tabular}{lcccccc}
\hline Espécies & \multicolumn{2}{c}{ P.actinea } & \multicolumn{2}{c}{ P. setacea } & \multicolumn{2}{c}{ P. serrato-digitata } \\
Estacas mortas & $\mathrm{n}$ & Média * & $\mathrm{n}$ & Média* & $\mathrm{n}$ & Média * \\
\hline Sem calo (\%) & 12 & $52,5 \mathrm{~A}$ & 12 & $44,8 \mathrm{~A}$ & 12 & $2,4 \mathrm{~B}$ \\
Com calo (\%) & 12 & $2,5 \mathrm{~A}$ & 12 & $8,5 \mathrm{~A}$ & 12 & $0,0 \mathrm{~A}$ \\
Enraizadas (\%) & 12 & $0,0 \mathrm{~A}$ & 12 & $4,7 \mathrm{~A}$ & 12 & $0,0 \mathrm{~A}$ \\
\hline Estacas mortas (\% total) & 12 & $56,8 \mathrm{~A}$ & 12 & $60,7 \mathrm{~A}$ & 12 & $2,4 \mathrm{~B}$ \\
\hline
\end{tabular}

*Médias com mesma letra, na linha, não diferem significativamente, pelo teste de Tukey**, a 5\%

**Para a análise estatística, os dados foram transformados por $\sqrt{x+1}$. 
TABELA 3 - Resultados médios obtidos pelo efeito de dois método de avaliação ( 2 nós e 3 nós), em 06 variáveis avaliadas, em 3 espécies de maracujá. Brasília-DF(2005).

\begin{tabular}{|c|c|c|c|c|c|}
\hline \multirow{2}{*}{$\begin{array}{l}\text { No. de nós } \\
\text { Estacas Vivas }\end{array}$} & \multicolumn{2}{|c|}{2 nós } & \multicolumn{2}{|c|}{3 nós } & \multirow[b]{2}{*}{$\mathrm{CV} \%$} \\
\hline & $\mathrm{n}$ & Média* & $\mathrm{n}$ & Média* & \\
\hline Sem calo $(\%)^{(1)}$ & 18 & $0,0 \mathrm{~A}$ & 18 & $1,8 \mathrm{~A}$ & 9,1 \\
\hline Com calo $(\%)^{(1)}$ & 18 & $5,7 \mathrm{~A}$ & 18 & $3,6 \mathrm{~A}$ & 15.4 \\
\hline Enraizadas sem broto (\%) ${ }^{(1)}$ & 16 & $6,7 \mathrm{~A}$ & 18 & $0,9 \mathrm{~B}$ & 16,3 \\
\hline Enraizadas com brotos $(\%)^{(1)}$ & 16 & $51,8 \mathrm{~A}$ & 18 & $53,2 \mathrm{~A}$ & 15,1 \\
\hline Comprimento do broto $(\mathrm{cm})^{(2)}$ & 14 & $23,0 \mathrm{~A}$ & 17 & $27,2 \mathrm{~A}$ & 17,1 \\
\hline Massa seca raizes/estaca $(\mathrm{g})^{(2)}$ & 16 & $0,1 \mathrm{~A}$ & 17 & $0,1 \mathrm{~A}$ & 0,3 \\
\hline
\end{tabular}

*Médias com mesma letra, na linha, não diferem significativamente, pelo teste de Tukey**, a 5\%

***ara a análise estatística, os dados foram transformados por $\sqrt[(1)]{x+1} \cdot \mathrm{e}^{(2)} \log (\mathrm{x}+10)$.

auxinas, as folhas também produzem carboidratos, que são importantes para o desenvolvimento das raízes. Desta forma, mantendo-se as folhas, não seria necessária a aplicação de auxinas. Segundo Meletti e Nagai (1992), a permanência de folhas nas estacas são determinantes no enraizamento de algumas espécies de passiflora. Por isso, alguns autores têm conseguido boas taxas de enraizamento em passifloras, sem a suplementação com auxinas (Meletti e Nagai, 1992; Salomão et al., 2002; Junqueira et al., 2002; Roncatto et al., 2003). Como foram mantidas duas folhas por estaca, provavelmente auxina não tenha sido um fator limitante.

A alta mortalidade das estacas de $P$. actinia e $P$. setacea poderia ser atribuída a alguma deficiência nos fatores externos, conforme citado por Rodrigues (1996), ou até mesmo a problemas fitossanitários. Dentre os fatores externos, a umidade durante o enraizamento e o estado da planta-matriz seriam os fatores mais prováveis. $P$. edulis f. flavicarpa parece ser menos exigente quanto à umidade, já que Meletti e Nagai (1992) obtiveram $75 \%$ de estacas brotadas, com uma média maior que $0,2 \mathrm{~g}$ de massa fresca de raízes por estaca, sem uso de nebulização, apenas mantendo o substrato úmido e uma proteção com saco plástico sobre a estaca, funcionando como câmara úmida. Já com $P$. serrato-digitata, esses autores não obtiveram muito sucesso, pois, apesar de obterem $72 \%$ de brotação, a maioria das estacas formaram apenas calos e rudimentos de raiz, mostrando que esta espécie é mais sensível, ou exigente, quanto ao fator umidade. Neste experimento, $P$. serrato-digitata apresentou desempenho significativo, pois, além de 94,2\% de enraizamento e brotação, a massa seca das raízes foi, em média, de $0,2 \mathrm{~g}$ por estaca, bem superior ao apresentado por Meletti e Nagai (1992), que obtiveram uma média de $0,08 \mathrm{~g}$ de massa fresca de raiz. Desta forma, não parece ter havido problema de falta de umidade, caso contrario, $P$. serratodigitata não teria tido esse desempenho significativo.

Observando-se as Tabelas 3 a 6, constata-se que não houve efeito significativo do tipo da estaca e do recipiente na sobrevivência ou mortalidade das estacas. Um dos efeitos de incrementar o volume do recipiente, é aumentar a disponibilidade de água para a planta (Oliveira et al., 1993; Carneiro, 1995). Mesmo assim, não houve efeito do recipiente na mortalidade (Tabela 6), confirmando a hipótese de que a umidade não foi fator limitante neste experimento. O tamanho da estaca também poderia influenciar, tanto nas reservas de carboidratos, como no volume de auxinas produzidas, o que proporcionaria maior sobrevivência e reação mais rápida de enraizamento. Neste caso, não houve efeito do tamanho da estaca na mortalidade.

Segundo Cervi (1997) e Marques et al. (2004), P. actinia floresce entre setembro e dezembro, frutificando entre dezembro e março. No Distrito Federal, observa-se a floração entre maio e agosto, e a frutificação, entre julho e novembro. As estacas foram coletadas no final de fevereiro de 2005, dois meses depois do final do período de frutificação, período no qual a planta provavelmente apresenta suas reservas internas bastante comprometidas. É neste período que Marques et al. (2004) observaram maior queda de folhas em P. actinia, confirmando ser este um período crítico para a planta. Koch et al. (2001) obtiveram média de $90 \%$ de enraizamento em $P$. actinia, em condições semelhantes a este experimento, concluindo que não haveria necessidade de uso de reguladores para o enraizamento de estacas semilenhosas dessa espécie. Estes autores coletaram as estacas entre junho e julho, justamente o período de pré-floração, contrastando com este experimento, no qual as estacas foram colhidas em fevereiro, período final de frutificação. Entretanto, Junqueira et al. (2002) obtiveram $42,3 \%$ de estacas enraizadas, sem regulador de crescimento, e média de $73 \%$ para estacas tratadas com ANA (entre 500 a $2000 \mathrm{mg} / \mathrm{L}$ ), nas mesmas condições deste experimento, em bandejas de 72 células, utilizando a mesma matriz, três anos mais nova . Os resultados de Junqueira et al. (2002) são cerca de 33\% superiores aos deste experimento (Tabela 1), cujos resultados indicam um total de estacas enraizadas de $31,8 \%$ (somando-se aquelas com e sem broto), contrastando com Koch et al. (2001), que apresentaram um resultado mais de $100 \%$ superior a Junqueira et al. (2002) e a este experimento. Entretanto, Junqueira et al. (2002), utilizando ANA, aproximam-se de Koch et al. (2001), chegando a $73 \%$ de enraizamento. Dados ainda não publicados indicam que estacas de $P$. actinia colhidas em setembro podem apresentar uma mortalidade de $25 \%$, enraizamento de $66,5 \%$ e responder significativamente à dose de $500 \mathrm{ppm}$ de AIB, sendo necessário um período superior a 60 dias para a formação das mudas. Isto leva a acreditar que exista uma interação entre o efeito "condição da matriz", relacionado à época de coleta das estacas e idade da matriz, com o efeito de aplicação de reguladores de crescimento.

O florescimento de $P$. setacea inicia-se entre julho e setembro, finalizando entre dezembro e março ( Meletti et al., 1992; Nunes e Queiroz, 2001; observações pessoais). No Distrito Federal, a floração ocorre entre maio e agosto, e a frutificação, entre julho e outubro. Junqueira et al. (2002) obtiveram 74,3\% de enraizamento de P. setacea, em condições semelhantes a este experimento, utilizando bandejas de 72 células, tendo inclusive colhido as estacas em março de 2002. Estas tinham um par de folhas e não foi constatado efeito de ANA no enraizamento. Neste caso, talvez o efeito "matriz" tenha proporcionado a diferença na eficiência de enraizamento entre Junqueira et al. (2002) e os resultados apresentados na Tabela 1, já que as estacas utilizadas por Junqueira et al. (2002) foram coletadas de planta diferente da utilizada neste experimento, mostrando que pode haver efeito segregante de predisposição genética ao enraizamento.

Dados ainda não publicados indicam que, para estacas colhidas em setembro, $P$. setacea pode apresentar uma mortalidade de $16 \%$, enraizamento de $52 \%$ e $37 \%$ de estacas com calo, aos 60 dias, indicando a necessidade de um período superior a 60 dias para formação de mudas. Neste caso, também não houve efeito de ANA, testado em doses de 500 a 2.000 ppm. Por outro lado, Roncatto et al. (2003), testando o enraizamento de estacas de $P$. setacea coletadas entre junho e outubro, e em abril, não conseguiram que nenhuma dessas estacas enraizassem.

Roncatto et al. (2003), observando algumas espécies de passifloras, concluíram que a sobrevivência, o número e o comprimento de raízes foram maiores na primavera. Portanto, a condição da matriz, seja em relação a época de retirada das estacas, seja em relação a predisposição genética, pode ser um fator importante. Experimentos devem ser estabelecidos para confirmar essa hipótese. 
A hipótese de problemas fitossanitários não foi descartada, já que algumas estacas mortas apresentaram sintomas de ataque de bradisia (Bradysia spp.), mosca com histórico de ocorrência no recinto do experimento. Segundo Oliveira (2000), as larvas de bradisia atacam a base das estacas e raízes de maracujá, prejudicam o enraizamento e podem provocar a morte das estacas. Além de danificar o sistema radicular, a larva poderá facilitar o ataque de doenças oportunistas. Neste caso, como a mortalidade de P. serrato-digitata foi bem pequena, talvez essa espécie seja resistente ou tolerante a bradisia. Outros experimentos seriam necessários para confirmar essas hipóteses.

Em relação às "estacas vivas", com e sem calo, a ocorrência deste tipo de estaca ficou apenas entre 0 e $10,2 \%$ das estacas plantadas, não apresentando diferenças relevantes entre os tratamentos propostos (Tabelas 01, 03 e 05).

O número de nós, um dos fatores estudados, não apresentou efeitos relevantes na formação de mudas (Tabela 3). Apesar de ter havido efeito significativo em relação à variável "estacas vivas enraizadas sem brotos", para a qual as estacas de 2 nós representaram $6,7 \%$ e as de 3 nós $0,9 \%$, este efeito é irrelevante, perante um total de "estacas vivas enraizadas com broto" entre 51,8 e 53,2\%. Para mortalidade (Tabela 4), também não houve efeito significativo entre

TABELA 4 - Resultados médios obtidos pelo efeito de dois métodos de avaliação ( 2 nós e 3 nós), em 04 variáveis avaliadas, em 3 espécies de maracujá. Brasília-DF (2005).

\begin{tabular}{lcrrrr}
\hline No. de nós & \multicolumn{2}{c}{2 nós } & \multicolumn{3}{c}{ 3 nós } \\
\cline { 2 - 6 } Estacas mortas & $\mathrm{n}$ & \multicolumn{1}{c}{ Média * } & \multicolumn{1}{c}{ Média* } & CV\% \\
\hline Sem calo (\%) & 18 & $29,4 \mathrm{~A}$ & 18 & $34,8 \mathrm{~A}$ & 19,3 \\
Com calo (\%) & 18 & $3,4 \mathrm{~A}$ & 18 & $4,1 \mathrm{~A}$ & 20,5 \\
Enraizadas (\%) & 18 & $2,3 \mathrm{~A}$ & 18 & $0,9 \mathrm{~A}$ & 15,2 \\
Total (\%) & 18 & $35,7 \mathrm{~A}$ & 18 & $40,5 \mathrm{~A}$ & 15,2 \\
\hline
\end{tabular}

*Médias com mesma letra, na linha, não diferem significativamente, pelo teste de Tukey**, a 5\%

**Para a análise estatística, os dados foram transformados por $\sqrt{x+1}$.

dois e três nós.

Por outro lado, o tipo recipiente utilizado teve efeito significativo e relevante para os objetivos desse trabalho (Tabela 5). O efeito foi mais relevante nas três principais variáveis de interesse: $\mathrm{o}$ porcentual de "estacas vivas enraizadas com brotos", o "comprimento do broto" e o "peso da massa seca das raízes". Nestas três variáveis, os melhores resultados foram obtidos com saco plástico, aumentando significativamente a qualidade das mudas produzidas. Segundo Carneiro (1995), na produção de mudas, as funções dos recipientes podem ser divididas em biológica e operacional. A função biológica é propiciar suporte e nutrição das mudas, proteger as raízes de danos mecânicos e desidratação, moldá-las em forma favorável para o desenvolvimento das mudas e maximizar a taxa de sobrevivência e crescimento inicial das mudas após o plantio. A função operacional é facilitar o manuseio no viveiro e no plantio. Este mesmo autor também

TABELA 5 - Resultados médios obtidos por dois tipos de recipientes em 06 variáveis avaliadas, em 3 espécies de maracujá. Brasília-DF (2005).

\begin{tabular}{lrrrrr}
\hline Recipiente & \multicolumn{2}{c}{ Bandeja } & \multicolumn{2}{c}{ Saco } \\
Estacas vivas & $\mathrm{n}$ & Média* $^{*}$ & \multicolumn{1}{c}{ Média* } & CV\% \\
\hline Sem calo (\%) $^{(1)}$ & 18 & $0,9 \mathrm{~A}$ & 18 & $0,8 \mathrm{~A}$ & 9,1 \\
Com calo (\%) $^{(1)}$ & 18 & $3,4 \mathrm{~A}$ & 18 & $5,9 \mathrm{~A}$ & 15,5 \\
Enraizadas sem broto (\%) $^{(1)}$ & 17 & $6,7 \mathrm{~A}$ & 17 & $0,9 \mathrm{~B}$ & 16,3 \\
Enraizadas com brotos (\%) $^{(1)}$ & 17 & $45,0 \mathrm{~B}$ & 17 & $59,9 \mathrm{~A}$ & 15,0 \\
Comprimento do broto (cm) $^{(2)}$ & 14 & $17,3 \mathrm{~B}$ & 17 & $33,5 \mathrm{~A}$ & 17,1 \\
Massa seca raizes/estaca $(\mathrm{g})^{(2)}$ & 16 & $0,1 \mathrm{~B}$ & 17 & $0,2 \mathrm{~A}$ & 0,3 \\
\hline
\end{tabular}

*Médias com mesma letra, na linha, não diferem significativamente, pelo teste de Tukey**, a 5\%

**Para a análise estatística, os dados foram transformados por ${ }^{(1)} \sqrt{x+1}$. e ${ }^{(2)} \log (\mathrm{x}+10)$ cita que o volume do recipiente afeta estas funções, ou seja, a disponibilidade de água e nutrientes; a deformação das raízes, e o manuseio das mudas no viveiro e no campo. Pode-se dizer que o volume do recipiente afeta direta e proporcionalmente suas funções biológicas e afeta de forma inversamente proporcional as suas funções operacionais.

Neste experimento, o saco plástico de $1.730 \mathrm{~cm}^{3}$ proporcionou um aumento de 18,2 vezes no volume do recipiente, em relação à bandeja, cuja célula comporta $95 \mathrm{~cm}^{3}$ de substrato. Para Carneiro (1995), a principal limitação do saco plástico, como recipiente, é no aspecto operacional, já que exige maior manuseio nas operações de viveiro e campo, além de poder proporcionar deformações no sistema radicular. Em bandejas, o pequeno volume do substrato proporciona menor disponibilidade de água para as mudas, requerendo maior frequiência de regas, o que, por sua vez, aumenta o lixiviamento de nutrientes, requerendo adubações mais frequientes, apesar de a bandeja facilitar as operações e economizar espaço dentro do viveiro.

Oliveira et al. (1993) também concluíram que o aumento do volume do substrato proporciona maior desenvolvimento da planta. Segundo Chaves et al. (2004), uma muda enxertada pode demorar até 150 dias para ficar pronta. Neste caso, é indiscutível a necessidade de um recipiente maior, que possa comportar, de forma satisfatória, o crescimento na muda durante todos esses dias. Entretanto, os resultados apresentados podem resultar de um confundimento entre o efeito do volume de recipiente e do tipo de substrato. Na bandeja, somente foi utilizado substrato Plantmax HT. Já no saco plástico, além do substrato Plantmax, ocupando $8 \mathrm{~cm}$ do topo do mesmo, utilizouse, no volume remanescente do saco, substrato de terra suplementado com esterco de gado e adubos minerais. Oliveira et al. (1993) testaram substrato Plantmax em comparação com substrato de terra (suplementado com esterco bovino e macronutrientes minerais), verificando que o primeiro foi superior, proporcionando melhor desenvolvimento das plântulas. Os resultados evidenciam a superioridade do tratamento "saco+plantmax+terra", mas também indicam a necessidade de outros estudos com diferentes volumes de recipientes e tipos de substrato.

TABELA 6 - Resultados médios obtidos por dois tipos de recipientes em 04 variáveis avaliadas, em 3 espécies de maracujá. Brasília-DF (2005).

\begin{tabular}{lcccrr}
\hline Recipiente & \multicolumn{2}{c}{ Bandeja } & \multicolumn{3}{c}{ Saco } \\
\hline Estacas mortas & $\mathrm{n}$ & \multicolumn{1}{c}{ Média * } & \multicolumn{1}{c}{ M } & Média* & CV\% \\
\hline Sem calo (\%) & 18 & $37,4 \mathrm{~A}$ & 18 & $27,0 \mathrm{~A}$ & 19,3 \\
Com calo (\%) & 18 & $3,4 \mathrm{~A}$ & 18 & $4,0 \mathrm{~A}$ & 20,5 \\
Enraizadas (\%) & 18 & $2,5 \mathrm{~A}$ & 18 & $0,8 \mathrm{~A}$ & 15,2 \\
Estacas mortas total (\%) & 18 & $44,0 \mathrm{~A}$ & 18 & $32,6 \mathrm{~A}$ & 15,2 \\
\hline
\end{tabular}

*Médias com mesma letra, na linha, não diferem significativamente, pelo teste de Tukey**, a 5\%

**Para a análise estatística, os dados foram transformados por $\sqrt{x+1}$.

\section{CONCLUSÕES}

1) P. serrato-digitata foi a espécie que apresentou melhor rendimento no enraizamento e na formação de mudas.

2) A alta taxa de mortalidade das estacas foi o principal fator limitante ao enraizamento de $P$. actinia e $P$. setacea.

3) Não houve diferenças relevantes entre estacas com dois e três nós.

4) O recipiente que proporcionou melhor desenvolvimento das estacas foi o saco plástico.

\section{REFERÊNCIAS}

CARNEIRO, J.G.A. Produção e controle de qualidade de mudas florestais. Curitiba: UFPR/FUPEF, 1995. p 309-356.

CERVI, A.C. Passifloraceae do Brasil: estudo do gênero passiflora L., subgênero passiflora. Fontqueria, Madrid, v.45, p.1-92, 1997. 
CHAVES, R.C.; JUNQUEIRA, N.T.V.; MANICA, I.; PEIXOTO, J.R.; PEREIRA, A.V.; FIALHO, J.F. Enxertia de maracujazeiro-azedo em estacas herbáceas enraizadas de espécies de passifloras nativas. Revista Brasileira de Fruticultura, Jaboticabal, v. 26, n.1. p. 102123, 2004.

FISCHER, I.H.; LOURENÇO, S.A.; MARTINS, M.C.; KIMATI, H.; AMORIM, L. Seleção de plantas resistentes e de fungicidas para o controle da podridão do colo do maracujazeiro causada por Nectria haematococca. Fitopatologia Brasileira, Brasília, v.30, p.250-258, 2005.

HARTMANN, H. T.; KESTER, D.E.; DAVIES JR, F.T.; GENEVE, R. L. Plant propagation: principles and practices. $6^{\text {th }}$ ed. New Jersey: Prentice Hall, 1997. p.288; 644.

JUNQUEIRA, N. T. V.; CHAVES, R. C.; MANICA, I.; PEIXOTO, J. R.; PEREIRA, A. V. E FIALHO, J. F. Propagação do maracujazeiroazedo por enxertia em estacas herbáceas enraizadas de espécies de passifloras nativas. Planaltina: Embrapa Cerrados, 2002. 15p. (Boletim de Pesquisa e Desenvolvimento, 39)

KOCH, R. C.; BIASI, L.A.; ZANETTE, F.; POSSAMAI, J.C. . Vegetative propagation of Passiflora actinia by semihardwood cuttings. Semina: Ciências Agrárias, Londrina, v. 22, n. 2, p. 165-167, 2001.

LIMA, A.A.; TRINDADE, A.V. Propagação. In: LIMA, A.A.; CUNHA, M.A.P. (Ed.).Maracujá: produção e qualidade na passicultura. Cruz das Almas: Embrapa Mandioca e Fruticultura, 2004. p.15-35.

LITTLE , M. T.; HILLS, F. J. Statistical methods in agricultural research. Davis : University of California, 1975. p.103-120.

MALDONADO, J.F.M. Utilização de porta-enxertos do gênero Passiflora para maracujazeiro-amarelo (Passiflora edulis Sims f. flavicarpa Deg.). Revista Brasileira de Fruticultura, Jaboticabal, v.13, n.2, p.51-54, 1991.

MARQUES, M.C.M.; ROPER, J.J.; SALVALAGGIO, A.P.B. Phenological patterns among plant life-forms in a subtropical forest in southern Brazil. Plant Ecology, Netherlands, v.173, p.203213, 2004.

MELETTI, L. M. M.; SOARES-SCOTT, M. D.; PINTO-MAGLIO, C. A. F. E MARTINS, F. P. Caracterização de germoplasma de maracujazeiro (Passiflora sp). Revista Brasileira de Fruticultura, Cruz das Almas, v.14, n.2, p.157-162, 1992.

MELETTI, L. M. M; FURLANI, P. R.; ALVARES, V.; SOARES-SCOTT, M. D.; BERNACCI, L.C.; FILHO, J.A.A. Novas tecnologias melhoram a produção de mudas de maracujá. O Agronômico, Campinas, v.54, n.1, p.30-33, 2002. Disponível em: <www.iac.sp.gov.br/Oagronomico/541/541_08t72.pdf>. Acesso em: 14 out. 2004

MELETTI, L. M. M.; NAGAI, V. Enraizamento de estacas de sete espécies de maracujazeiro (Passiflora spp). Revista Brasileira de Fruticultura, Cruz das Almas, v.14, n. 2, p. 163-168, 1992.
NUNES, T. S.; QUEIROZ, L. P. A família Passifloraceae na chapada diamantina, Bahia, Brasil. Sitientibus: Série Ciências Biológicas, Feira de Santana, v.1, n.1, p.33-46. 2001

MENEZES, J.M.T.; OLIVEIRA, J.C. de; RUGGIERO, C.; BANZATTO, D. A. Avaliação da taxa de pegamento de enxertos de maracujáamarelo sobre espécies tolerantes à "morte prematura de plantas". Científica, São Paulo, v.22, n.1, p.95-104, 1994

OLIVEIRA, J.A. Efeito dos substratos artificiais no enraizamento e no desenvolvimento de maracujá-azedo e doce por estaquia. 2000. 71 f. Dissertação (Mestrado) - Faculdade de Agronomia e Medicina Veterinária, Universidade de Brasília, Brasília, 2000.

OLIVEIRA, R.P. de; SCIVITTARO, W.B.; VASCONCELLOS, L.A.B.C. de. Avaliação de mudas de maracujazeiro em função do substrato e do tipo de bandeja. Scientia Agrícola, Piracicaba, v.50, n.2, p.261-266, 1993.

PIO-RIBEIRO, G.E.; MARIANO, R.L.R. Doenças do maracujazeiro. In: KIMATI, H.; AMORIM, L. BERGAMIN FILHO, A.; CAMARGO, L.E.A.; REZENDE, J.A.M. (Ed.). Manual de fitopatologia. 3.ed. São Paulo: Agronômica Ceres, 1997. p.528-533.

RODRIGUES, G.C. Aspectos fisiológicos da propagação de fruteiras. In: PINTO, A.C.Q. (Coord.).Produção de mudas frutíferas sob condições do ecossistema de Cerrados. Planaltina: Embrapa-CPAC ,1996. p.29-33. (Documentos, 62),

RONCATTO, G.; FILHO, G.C.N; RUGGIERO, C.; OLIVEIRA, J.C.; MARTINS, A.B.G. Enraizamento de espécies de maracujazeiro (Passiflora spp.) propagadas por estaquia herbácea. In: REUNIÃO ANUAL DA ISTH, 49., REUNIÓN ANUAL DE LA ISTH, 49., ANNUAL MEETING OF THE ISTH, 49., 2003, Fortaleza, CE, Brasil, Resumos... p.107.

RONCATTO, G.; OliVEIRA, J. C. de; RUGGIERO, C. et al. Comportamento de maracujazeiros (Passiflora spp.) quanto à morte prematura. Revista Brasileira de Fruticultura, Jaboticabal, v.26, n.3, p.552-554, 2004..

RUGGIERO, C.; OLIVEIRA, J. C. Enxertia do maracujazeiro. In: SIMPÓSIO BRASILEIRO SOBRE A CULTURA DO MARACUJAZEIRO, 5., 1998, Jaboticabal. Anais... Jaboticabal: FUNEP, 1998. p.70-92.

SALOMÃO, L.C.C.; PEREIRA, W.E.; DUARTE, R.C.C.; SIQUEIRA, D.L. Propagação por estaquia dos maracujazeiros doce (Passiflora alata Dryand.) e amarelo (P. edulis f. flavicarpa O. Deg.). Revista Brasileira Fruticultura, Jaboticabal, v. 24, n.1, p. 63-167, 2002.

SANTOS FILHO, H. P. Doenças do sistema radicular do maracujazeiro. In: SIMPÓSIO BRASILEIRO SOBRE A CULTURA DO MARACUJAZEIRO, 5., Jaboticabal. Anais... Jaboticabal: FUNEP, 1998. p.244-254.

WOODWARD, A.W.; BARTEL, B. Auxin: regulation, action, and interaction. Annals of Botany, London, v.95, p.707-735, 2005. 